\title{
The Hydrogen Breath Test: New Uses for an Old Test
}

Kok-Ann Gwee, FRCP, PhD

National University of Singapore, Gleneagles Hospital, Singapore

\section{Article: Patients with irritable bowel syndrome exhale more hydrogen than healthy subjects in fasting state} (J Neurogastroenterol Motil 2010;16:299-305)

The paper by Ghoshal et al in this issue of the journal reminds us that we can still find new uses for old tests. In this study, patients with the irritable bowel syndrome (IBS) were reported to exhale higher basal breath hydrogen than asymptomatic controls. While previous studies had found that IBS patients demonstrated greater breath hydrogen excretion after fibre rich meals and lactulose, they had not reported higher basal levels.

In order to appreciate the significance of this observation, the basis of the hydrogen breath test should be reviewed. Calloway et $\mathrm{al}^{1}$ observed that intestinal hydrogen gas was released by the human intestinal microflora, and that the measurement of breath hydrogen could be used to monitor intestinal hydrogen production. At about the same time Levitt ${ }^{2,3}$ provided evidence that hydrogen gas in the intestine is generated almost exclusively from microbial fermentation of unabsorbed carbohydrates. From these observations, test protocols employing the monitoring of breath hydrogen levels were developed to detect malabsorption of various mono- and disaccharide sugars (eg, fructose, glucose and lactose) and to measure the oro-caecal transit time. ${ }^{4}$ The physico-chemical basis for the hydrogen breath test is that hydrogen being a small molecule diffuses rapidly across the colonic mucosa, where it enters the blood stream to be circulated to the lungs where it is excreted in the breath. Breath hydrogen level rises rapidly in response to intestinal hydrogen release as a measurable hydrogen response can be recorded within 2 minutes following introduction of lactulose, an unabsorbable disaccharide. ${ }^{5}$ Recent studies from John Hunter's laboratory in Cambridge demonstrated that when IBS patients were given treatments that resulted in a reduction of intestinal gas production, breath hydrogen excretion also reduced in parallel. ${ }^{6}$

What are the roles of the hydrogen breath test in the investigation of IBS? Lactose and fructose intolerance may contribute to the development of IBS symptoms, particularly, bloating, flatulence, cramps and diarrhoea. In IBS patients, diarrhoea symptoms are associated with rapid small intestinal transit, while constipation is associated with delayed transit. As breath hydrogen can be used as a surrogate measure of intestinal gas production, we can use this to study bloating and other gas related symptoms. Unfortunately while Ghoshal et al, had postulated that bloating may result from increased intestinal gas production, their study did not test for an association between bloating and basal breath hydrogen. More recently, small intestinal bacterial overgrowth

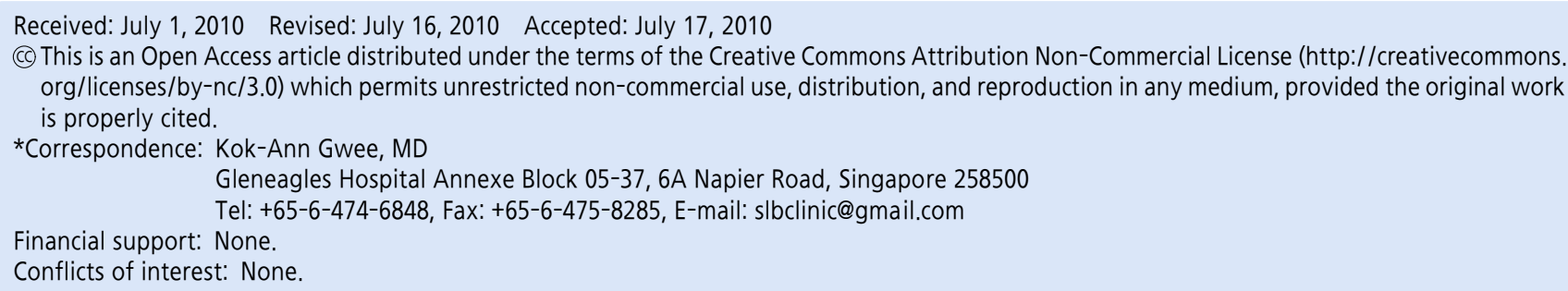


(SIBO) and coeliac disease have been also been implicated in the pathogenesis of IBS, and both of these conditions could have contributed to the high basal breath hydrogen reported by Ghoshal et al in their cohort of IBS patients. While they recognised SIBO as a possible contributing factor, they appear to have overlooked the possibility of undetected coeliac disease as a confounding factor. Studies from the west suggest that patients with IBS criteria may have sub-clinical coeliac disease, and studies from India have reported a rising incidence of coeliac disease, particularly in the north. ${ }^{7,8}$ In fact, Nunes et al, ${ }^{9}$ had reported high basal breath hydrogen in coeliac disease.

The other noteworthy finding in Ghoshal's study was the correlation of breath hydrogen levels with the number of stools. If we look carefully at the symptom profile of their patients, we find that the majority had diarrhoea type symptoms; their mean number of stools at 25 a week works out to more than 3 a day, with $95 \%$ reporting loose stools and $84 \%$ more frequent stools at the onset of pain. This suggests a possible correlation between basal breath hydrogen level and rapid intestinal transit. Previous studies from India have documented relatively shorter intestinal transit times in the Indian population than those reported in the west. ${ }^{10}$ In a society like India, where many people adopt a largely vegetarian diet, especially given the prevailing belief in the benefits of a high fibre diet, one wonders how good the compliance was in Ghoshal's subjects. Thus, we can postulate that the residue of a high fibre diet, coupled with rapid transit through the small intestine, could have combined to push a large load of fermentable carbohydrates into the caecum at the start of breath hydrogen measurement. Previous studies from the UK had shown that hydrogen levels are barely detected in the breath if the subject is carefully prepared. ${ }^{11}$ One of the requirements is that the subject must not be on a high fibre diet.

One lesson to draw from this analysis of the possible factors contributing and confounding the findings in Ghoshal's study, is that future studies must take into account the need to determine the type of diet consumed, and in particular dietary fibre intake, and also impose stricter checks and controls in the pre-test preparation. However, even taking a possible confounding effect into account, the observations by Ghoshal et al, still provides us with food for thought. Is it possible after all, that a high level of fibre intake could be contributing to the pathogenesis of IBS symptoms in the Indian population? In this context, the hydrogen breath test may find new life as an important tool in epidemiological studies comparing different diets in different populations and how this contributes to the development of IBS.

\section{References}

1. Calloway DH, Colasito DJ, Mathews RD. Gases produced by human intestinal microflora. Nature 1966;212:1238-1239.

2. Levitt MD. Production and excretion of hydrogen gas in man. N Engl J Med 1969;281:122-127.

3. Levitt MD, Bond JH Jr. Volume, composition, and source of intestinal gas. Gastroenterology 1970;59:921-929.

4. Bond JH Jr, Levitt MD, Prentiss R. Investigation of small bowel transit time in man utilising pulmonary hydrogen $\left(\mathrm{H}_{2}\right)$ measurements. J Lab Clin Med 1975;85:546-555.

5. Read NW, Al Janabi MN, Bates TE, Barber DC. Effect of gastrointestinal intubation on the passage of a solid meal through the stomach and small intestine in humans. Gastroenterology 1983;84:15681572.

6. Dear KL, Elia M, Hunter JO. Do interventions which reduce colonic bacterial fermentation improve symptoms of irritable bowel syndrome? Dig Dis Sci 2005;50:758-766.

7. Sanders DS, Carter MJ, Hurlstone DP, et al. Association of adult coeliac disease with irritable bowel syndrome: a case-control study in patients fulfilling ROME II criteria referred to secondary care. Lancet 2001;358:1504-1508.

8. Sood A, Midha V, Sood N, Kaushal V, Puri H. Increasing incidence of celiac disease in India. Am J Gastroenterol 2001;96:2804-2805.

9. Nunes DP, Kelly CP, Nolan NPM, O'Connor MP, Weir DG. Fasting breath hydrogen, small intestinal bacterial overgrowth and intestinal transit in coeliac disease. Eur J Gastroenterol Hepatol 1991;3:313-319.

10. Ghoshal UC, Gupta D, Kumar A, Misra A. Colonic transit time by radio-opaque markers to investigate constipation: validation of a new protocol for population with rapid gut transit. Natl Med J India 2007;20:225-229.

11. Thompson DG, Binfield P, De Belder A, O'Brien J, Warren S, Wilson M. Extra-intestinal influences on exhaled breath hydrogen measurements during the investigation of gastrointestinal disease. Gut 1985;26:1349-1352. 